\title{
Catastrophic expenditure and impoverishment of patients affected by 7 rare diseases in China
}

\author{
Xiao-Xiong Xin ${ }^{1}$, Xiao-Dong Guan ${ }^{1,2}$ and Lu-Wen Shi ${ }^{1,2^{*}}$
}

\begin{abstract}
Background: China is actively promoting regulation of rare diseases, rare disease and orphan drugs have been formally incorporated into the national planning. However, few studies have been done to evaluate the affordability of rare disease patients in China. This study aims to provide policy recommendations for the establishment of social security mechanism for rare diseases in China, so as to address the problem of poverty caused by these diseases.

Methods: A total of 7 rare diseases were selected by Delphi method. Affordability of treatment for the 7 rare diseases was assessed through annual per capital income, catastrophic expenditure and impoverishment expenditure among urban and rural residents in China.

Results: Assessed through annual per capital income, health expenditure for the 7 rare diseases are all rather high. The highest health expenditure is equivalent to income of 69.34 years of one urban resident, and the burden is heavier for rural residents. Through catastrophic expenditure assessment, proportions of the population experiencing catastrophic expenditure caused by the 7 rare diseases are all under $0.167 \%$. However, once one is ill and taking medications, he will suffer from catastrophic health expenditure. Through impoverishment expenditure assessment, the proportions of impoverishment payment are low among both urban and rural residents, but the 7 rare diseases could lead nearly 4.6 million people into poverty on a national scale.

Conclusion: The affordability of treatment for rare disease as well as orphan drugs is rather poor. Residents of different income levels all have difficulties to afford the treatment for rare diseases, so poverty caused by rare diseases is quite widespread. Therefore, social security mechanism for rare disease patients should be established and specific payment pattern for orphan drugs should be set up.
\end{abstract}

Keywords: Rare disease, Orphan drug, Catastrophic expenditure, Impoverishment effect, Affordability

\section{Background}

Rare disease refers to the disease with low incidence which is hard to be diagnosed and treated [1]. Therapeutic drugs for rare diseases are often called orphan drugs. The standard of rare disease varies across countries [2]. Since 1980s, the legislation on rare diseases and polices towards orphan drugs have been gradually implemented in developed countries and regions [3].

Although China is actively promoting regulation of rare diseases, there is no legislation for rare disease up

\footnotetext{
* Correspondence: 102385308@qq.com

'Department of Pharmacy Administration and Clinical Pharmacy, School of Pharmaceutical Sciences, Peking University, Beijing 100191, China

${ }^{2}$ International Research Center of Medicinal Administration, Peking University, Beijing 100191, China
}

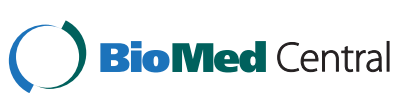

(c) 2016 The Author(s). Open Access This article is distributed under the terms of the Creative Commons Attribution 4.0 International License (http://creativecommons.org/licenses/by/4.0/), which permits unrestricted use, distribution, and reproduction in any medium, provided you give appropriate credit to the original author(s) and the source, provide a link to the Creative Commons license, and indicate if changes were made. The Creative Commons Public Domain Dedication waiver (http://creativecommons.org/publicdomain/zero/1.0/) applies to the data made available in this article, unless otherwise stated. or official definition on rare disease [4]. In 2010 , experts from Genetics Group of Chinese Medical Association put forward an unofficial standard for rare disease on Symposium on Definition of Rare Disease, which is genetic disease with prevalence rate lower than $1 / 500,000$ in population or incidence rate lower than $1 / 10,000$ in neonate. Current regulations only include incentive policies for registration and approval of orphan drugs. There are no detailed rules for development and pricing of orphan drugs. The nationwide reimbursement system for rare diseases has not been established [5]. With the rapid economic development, rare diseases are causing rising social concentration throughout the country. In January 
2016, National Experts Committee of Diagnosis and Security of Rare Disease was set up under the leading of National Health and Family Planning Commission of People's Republic of China. In February of the same year, Chinese Premier Li Keqiang proposed to promote the development and update of pharmaceutical industry at State Council executive meeting, emphasizing improving the industrial development of orphan drugs. It symbolised that rare disease and orphan drugs have been formally incorporated into the national planning.

The cost of diagnosis and treatment for rare disease is high, which may impoverish the patients and their families. Rare disease is not only a problem in health system but extends to social sphere. The design of legal system and policies of rare disease in China are far behind the need for pharmaceutical and social development. Therefore, it is of great social significance to explore the feasibility of establishing social security mechanism for rare diseases in China.

There have been some researches to investigate the medical insurance policies of rare diseases and orphan drugs in China, but few studies have been done to evaluate the affordability of rare disease patients in China [6]. Using Delphi method to select sampled rare diseases, our study assessed the affordability and providing suggestions of establishing social security mechanism for rare diseases.

\section{Methods}

Our study evaluated the affordability of medicines by the following three methods. Firstly, WHO and Health Action International (HAI) have proposed a standard survey tool that applies the Lowest Paid unskilled Government Worker (LPGW) [7]. Affordability is then expressed in terms of the number of days the LPGW has to work to afford a course of treatment. Secondly, the catastrophic approach, i.e. the payment for a commodity is deemed catastrophic (unaffordable) when its cost exceed a certain percentage of household resources, was calculated [8]. Thirdly, according to the impoverishment approach, affordability of medicines was evaluated by measuring the proportion of the population that drops below the poverty line due to health expenditures of the diseases [9].

Due to the large gap between urban and rural areas in China, the affordability of rare diseases in this study intended to be assessed separately by urban and rural residents, and the affordability would be analysed by the above-mentioned three methods individually.

\section{Sampled diseases}

Rare disease and therapeutic regimen needed to be identified to determine the health expenditure. This study used the Delphi method to conduct two rounds' consultation of medical experts in Beijing. All of the ten experts were chief physicians from tertiary hospitals in Beijing, who specialised in department of neurology, cardiology, paediatrics, dermatology, respiratory, nephrology, ophthalmology and haematology and had rich experience on diagnosis and treatment of rare diseases. The selection criteria of diseases were to choose diseases with clear diagnosis standard and definite medical therapy. Then the selected diseases were categorized into three levels according to their health expenditure: health expenditure less than GDP per capita (level I), health expenditure between GDP per capita and three times of GDP per capita (level II), and health expenditure over three times of GDP per capita (level III). After the first round of consultation through email, 19 diseases were obtained (7 in level I, 6 in level II and 6 in level III). To further narrow down the disease scope, the experts were asked to select 2-3 diseases from each level. Eventually 7 rare diseases were selected which could be effectively treated with different health expenditures. After discussion of the experts, the standard medical therapy and annual health expenditure were determined. The prevalence data were retrieved from the European Orphanet database [10]. Because rare diseases usually require longterm treatment, this study used health expenditure per year as the measurement, as shown in Table 1.

\section{Per capital income approach}

According to WHO/HAI standard survey tool, the affordability of medicines could assessed through annual per

Table 1 Sampled rare diseases and medicines

\begin{tabular}{lllll}
\hline Rare disease & Prevalence & Therapeutic regimen & $\begin{array}{c}\text { Health expenditure } \\
\text { per year (1,000 yuan) }\end{array}$ & $\begin{array}{c}\text { Health expenditures as a } \\
\text { share of per capita GDP }\end{array}$ \\
\hline Duchenne Muscular Dystrophy (DMD) & $5 / 100000$ & Methylprednisolone Tablet, 0.6 mg/Kg/day & 1.20 & $0-1$ \\
Alport Syndrome (AS) & $2 / 100000$ & ACEl combined with ARB & 7.50 & $0-1$ \\
Tuberous Sclerosis Complex (TSC) & $8.8 / 100000$ & Sirolimus Tablet, 1 mg bid & 40 & $0-1$ \\
Amyotrophic Lateral Sclerosis (ALS) & $5 / 100000$ & Riluzole Tablet, $50 \mathrm{mg}$ bid & 55 & $1-3$ \\
Idiopathic Pulmonary Fibrosis (IPF) & $16.7 / 100000$ & Pirfenidone Tablet, 200-400 mg tid & 86 & $1-3$ \\
Pulmonary Arterial Hypertension (PAH) & $5 / 100000$ & Bosentan Tablet, 125 mg bid & 240 & $>3$ \\
Gaucher Disease (GD) & $1 / 100000$ & Imiglucerase for Injection, 60 U/kg, fortnightly & 2000 & $>3$ \\
\hline
\end{tabular}


capital income [7]. We used this method to assess the affordability of medicines for rare diseases. Result is expressed in terms of the number of years, which measuring health expenditures with the share of annual per capital income. Health expenditures of sampled rare diseases of urban and rural residents were calculated separately.

\section{Catastrophic approach}

WHO defined expenditure as catastrophic if a household's health expenditure exceeded $40 \%$ of remaining income after subsistence needs have been met [11]. We calculated the minimum annual income needed for avoiding catastrophe by this standard. We needed Chinese income distribution to calculate the catastrophe population and catastrophe rate. Income distribution curves of urban and rural residents were simulated separately by in this paper. We used annual disposable income per capita as coordinate, then divided the population into five groups and took the proportion of the population as the abscissa. The income of each group was hypothesized to have linear relation with the proportion of the population, as shown in the following equation:

$$
y_{i}=a_{i} x_{i}+\mathrm{b} i
$$

in which y was annual disposable income per capita and $\mathrm{x}$ was the proportion of the population. Distribution curves of annual per capita disposable income of urban and rural residents were shown in Figs. 1 and 2 [12]. According to the simulation curves, catastrophe rate caused by certain diseases could be calculated:

Catastrophe Rate $=\left(\right.$ The Minimum Annual Income to avoid Catastrophe- $\left.\mathrm{b}_{i}\right) /$ $a i \times 100 \%$

In addition, our study adjusted the threshold of catastrophic expenditure (30 \%, $50 \%)$ for sensitivity analysis.

\section{Impoverishment approach}

The impoverishment approach investigates the extent to which expenditures on medicines push people's income below a certain absolute threshold. The method aims to compare the proportion of the population below the poverty line before and after the procurement of medicines except those who had been already below the threshold before the procurement. This method needed to determine urban and rural poverty line at first, which is determined based on national rural and urban Minimum Living standard and graphed in Figs. 1 and 2. The most recent poverty line was issued in 2011, which was only applied for rural residents. Since rural and urban residents were considered as two groups in the study, the annual per capita subsidy for low-income residents in 2014 was taken as the poverty line for urban residents, which had already been done by other research [13]. Based on this standard, urban poverty line is 3432 yuan and rural poverty line is 1548 yuan. There are 18.77 million urban residents and 52.07 million rural residents [14].

Impoverishment Rate $=$ amounts of impoverished population caused by disease/amounts of population not in poverty before disease $\times 100 \%$.

\section{Results}

Per capita income evaluation

In 2014, annual per capita disposable income of urban and rural residents is 28,843.9 yuan and 10,488.9 yuan respectively. Results are shown in Table 2.

i. Taking average annual income as reference, only the health expenditure of DMD and AS is lower than annual per capita income of urban and rural residents. That is to say, the health expenditure of

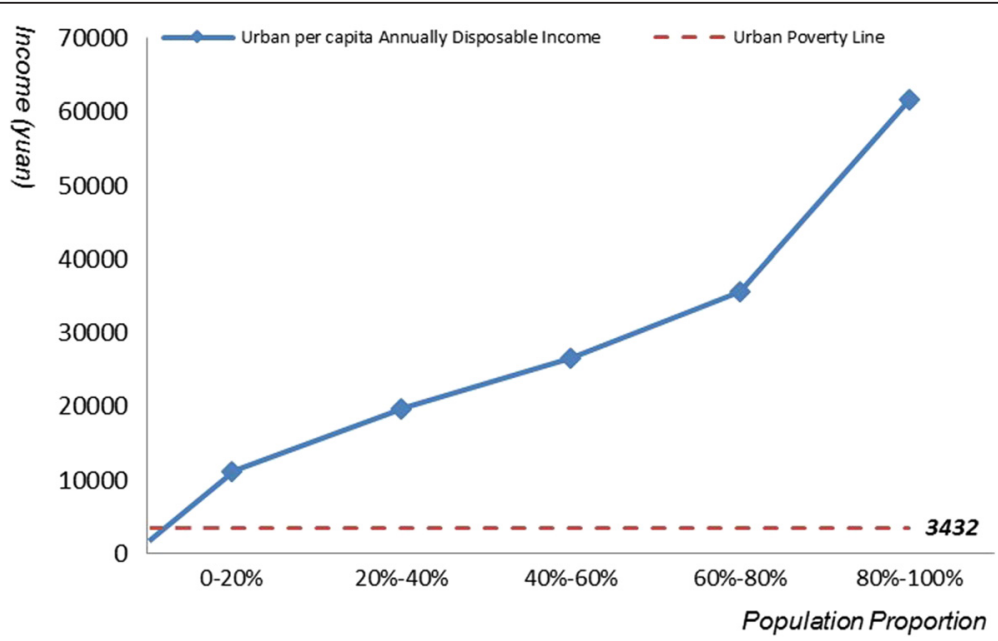

Fig. 1 Distribution curve of Chinese urban per capita annually disposable income 


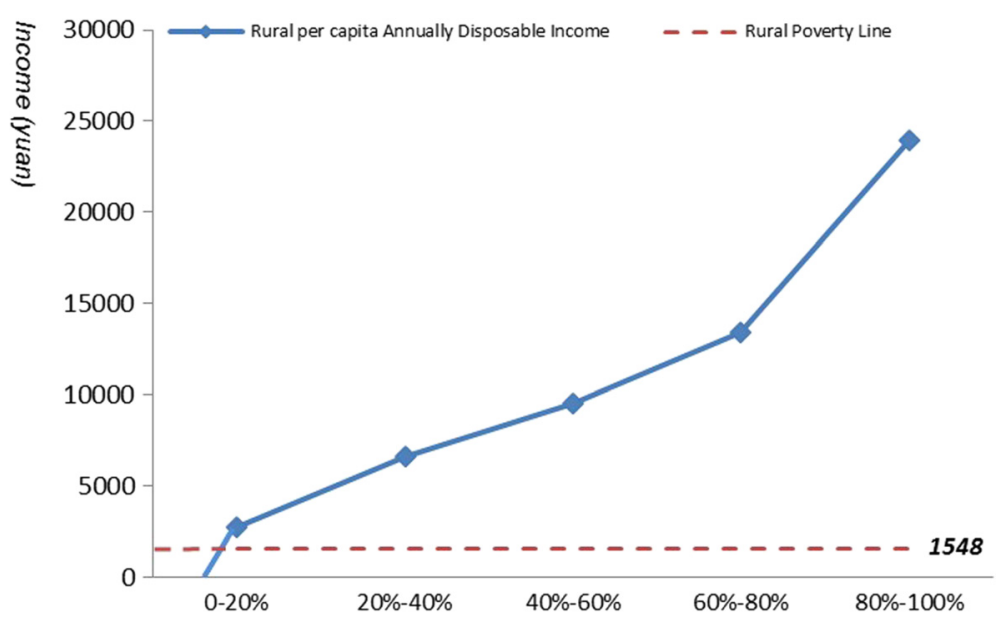

Fig. 2 Distribution curve of Chinese rural per capita annually disposable income

rare disease is high, which generally means heavy burden on patients, especially to those rural residents with low income.

ii. The health expenditure of some rare diseases is terribly high. For example, the average annual health expenditure of GD is equivalent to 69.34 times of average annual income of urban residents and 32 times of high-income groups (top $20 \%$ ) of urban residents whose average annual disposable income are 61,615 yuan. For these rare diseases, the patients cannot afford the medical expenses for treatment.

\section{Catastrophic evaluation}

According to the catastrophic method and income distribution curve, we calculated the population and proportion of urban or rural residents facing catastrophic expenditure owing to the treatment of 7 sampled rare diseases. Catastrophe and sensitive analysis results are shown in Table 3, taking the prevalence of disease into consideration.

Table 2 Affordability of the sampled rare diseases measured by per capita annually disposable income

\begin{tabular}{llll}
\hline Rare disease & $\begin{array}{l}\text { Health expenditure } \\
\text { per year (1,000 yuan) }\end{array}$ & $\begin{array}{l}\text { Health expenditures as a } \\
\text { share of per capita annually } \\
\text { disposable income (year) }\end{array}$ \\
\cline { 3 - 4 } & 1.20 & 0.04 & Urban \\
\hline DMD & 7.50 & 0.26 & 0.11 \\
AS & 40 & 1.39 & 3.81 \\
TSC & 55 & 1.91 & 5.24 \\
ALS & 86 & 2.98 & 8.20 \\
IPF & 240 & 8.32 & 22.88 \\
PAH & 2000 & 69.34 & 190.68 \\
GD & & &
\end{tabular}

The study finds that, i. Taking $40 \%$ as threshold, the catastrophe rate of sampled rare diseases does not exceed $0.1670 \%$ o throughout the country, and the proportion of patients experiencing catastrophic expenditure with DMD is only $0.0015 \%$. However, taking the whole population into consideration, DMD will cause $6000 \mathrm{pa}-$ tients to experience catastrophic expenditure in China. There are about 7000 rare diseases known worldwide, but there is no statistical data in China. The rare disease patients who may incur catastrophic expenditure should be paid serious attention to.

ii. Except for DMD and ALS, the catastrophe rate of the other sampled rare diseases has no difference between urban and rural areas, which is equivalent to the prevalence of relevant rare diseases. It shows that these five diseases would bring huge burden to patients, who cannot afford the health expenditure. Once one is ill and taking medicines, he will suffer from catastrophic expenditure. Taken $40 \%$ as threshold, a patient need an average annual income of over 6.4 million yuan to avoid catastrophic expenditure.

iii. Taken $40 \%$ as threshold, DMD and AS have different influences on urban and rural residents. These two diseases cause 1.09 thousand and 6.41 thousand urban residents, 4.85 thousand and 11.18 thousand rural residents respectively to experience catastrophic expenditure.

iv. The sensitive analysis shows that the change of threshold leads no changes among sampled diseases except for the probability of catastrophic expenditure for patients with DMD and AS. It is indicated the stability of this evaluation method.

\section{Impoverishment evaluation}

According to the impoverishment method, with the combination distribution curve and poverty line data, considering the prevalence of sampled rare diseases, 
Table 3 Catastrophic effect of expenditures and sensitivity analysis of sampled rare diseases

\begin{tabular}{|c|c|c|c|c|c|c|}
\hline \multirow[t]{2}{*}{ Rare disease } & \multirow[t]{2}{*}{ Threshold } & \multirow{2}{*}{$\begin{array}{l}\text { The minimum annually income } \\
\text { to avoid catastrophe }\end{array}$} & \multicolumn{2}{|c|}{ Catastrophe rate } & \multicolumn{2}{|c|}{ Catastrophe population } \\
\hline & & & Urban (\%o) & Rural (\%o) & Urban $(1,000)$ & Rural $(1,000)$ \\
\hline \multirow[t]{3}{*}{ DMD } & $30 \%$ & 5147 & 0.0021 & 0.0112 & 1.56 & 6.93 \\
\hline & $40 \%$ & 3860 & 0.0015 & 0.0078 & 1.09 & 4.85 \\
\hline & $50 \%$ & 3088 & 0.0011 & 0.0058 & 0.81 & 3.61 \\
\hline \multirow[t]{3}{*}{ AS } & $30 \%$ & 32168 & 0.0125 & 0.0200 & 9.33 & 12.37 \\
\hline & $40 \%$ & 24126 & 0.0086 & 0.0181 & 6.41 & 11.18 \\
\hline & $50 \%$ & 19301 & 0.0058 & 0.0162 & 4.37 & 10.04 \\
\hline \multirow[t]{3}{*}{ TSC } & $30 \%$ & 171563 & 0.0880 & 0.0880 & 65.93 & 54.44 \\
\hline & $40 \%$ & 128673 & 0.0880 & 0.0880 & 65.93 & 54.44 \\
\hline & $50 \%$ & 102938 & 0.0880 & 0.0880 & 65.93 & 54.44 \\
\hline \multirow[t]{3}{*}{ ALS } & $30 \%$ & 235900 & 0.0500 & 0.0500 & 37.46 & 30.93 \\
\hline & $40 \%$ & 176925 & 0.0500 & 0.0500 & 37.46 & 30.93 \\
\hline & $50 \%$ & 141540 & 0.0500 & 0.0500 & 37.46 & 30.93 \\
\hline \multirow[t]{3}{*}{ IPF } & $30 \%$ & 368861 & 0.1670 & 0.1670 & 125.11 & 103.32 \\
\hline & $40 \%$ & 276646 & 0.1670 & 0.1670 & 125.11 & 103.32 \\
\hline & $50 \%$ & 221317 & 0.1670 & 0.1670 & 125.11 & 103.32 \\
\hline \multirow[t]{3}{*}{ PAH } & $30 \%$ & 1029380 & 0.0500 & 0.0500 & 37.46 & 30.93 \\
\hline & $40 \%$ & 772035 & 0.0500 & 0.0500 & 37.46 & 30.93 \\
\hline & $50 \%$ & 617628 & 0.0500 & 0.0500 & 37.46 & 30.93 \\
\hline \multirow[t]{3}{*}{ GD } & $30 \%$ & 8578167 & 0.0100 & 0.0100 & 7.49 & 6.19 \\
\hline & $40 \%$ & 6433626 & 0.0100 & 0.0100 & 7.49 & 6.19 \\
\hline & $50 \%$ & 5146900 & 0.0100 & 0.0100 & 7.49 & 6.19 \\
\hline
\end{tabular}

proportion of impoverishment and number of impoverished patients are showed in Table 4.

i. Impoverishment rate of sampled rare diseases is low among urban and rural residents. Among the 7 disease, impoverishment rate of IPF is the highest, up to $0.1670 \%$ o both in urban and rural residents, while impoverishment rate of DMD in urban residents is the lowest $(0.0006 \%$ o). However, the sampled rare diseases could lead 459.64 thousand people into poverty on a national scale. It shows that the problem of impoverishment by rare diseases in China is rather severe and should be paid more attention.

ii. Among the 7 diseases, the treatment burden of AS is relatively light and the impoverishment population of AS in rural residents is significantly more than that of urban residents, which indicate that policy makers should pay more attention to the disadvantaged groups when implementing policies. AS lead 1.08 thousand urban and 4.76 thousand rural residents into poverty.

iii. IPF leads more people to poverty than the other 6 rare diseases, which could impoverish 121.98

Table 4 Impoverishing effect of sampled rare diseases

\begin{tabular}{|c|c|c|c|c|}
\hline \multirow[t]{2}{*}{ Rare disease } & \multicolumn{2}{|l|}{ Urban } & \multicolumn{2}{|l|}{ Rural } \\
\hline & Impoverishment rate (\%o) & Impoverishment population $(1,000)$ & Impoverishment rate (\%) & Impoverishment population $(1,000)$ \\
\hline DMD & 0.0006 & 0.43 & 0.0008 & 0.46 \\
\hline AS & 0.0015 & 1.08 & 0.0084 & 4.76 \\
\hline TSC & 0.0663 & 48.45 & 0.0880 & 49.86 \\
\hline ALS & 0.0436 & 31.86 & 0.0500 & 28.33 \\
\hline IPF & 0.1670 & 121.98 & 0.1670 & 94.62 \\
\hline $\mathrm{PAH}$ & 0.0500 & 36.52 & 0.0500 & 28.33 \\
\hline GD & 0.0100 & 7.30 & 0.0100 & 5.67 \\
\hline
\end{tabular}


thousand urban and 94.62 thousand rural residents respectively.

iv. Impoverishment rate of IPF, PAH, GD in urban residents and that of TSC, ALS, IPF, PAH, GD in rural residents are equal to corresponding prevalence. This result indicates that once one is ill, he will fall into poverty for health expenditure.

\section{Discussion}

Simoens found the price of orphan drugs is inversely proportional to the prevalence rate of the rare diseases treated [15]. Of the 7 surveyed diseases, however the aforesaid phenomenon was not observed. Our study showed that the prevalence rate of DMD, ALS and PAH were the same, while the health expenditure for the three diseases varied from 1200 to 240,000 yuan. The results also shown that poor households were less able to afford the health expenditure than richer households, which were consistent with other studies [16-18]. However, some rare diseases have higher incidence in lowincome residents, such as leukemia in Gansu Province (higher in rural) and malaria in China [19, 20]. Therefore disease burden of rural residents should be paid more attention. Furthermore, the reality cannot fully be captured by the results of affordability assessment, because many patients would rather not use healthcare service than become impoverished [21,22].

High price of orphan drugs is the direct cause of heavy burdens for rare diseases patients, which is consistent with other studies [23]. Therefore, there is an urgent need to cut down the price of these drugs. However, as the market scale is relatively small and most orphan drugs are monopolized, cutting down the prices alone still cannot make the drugs become affordable to many patients. It takes time to define rare disease and kickstart relevant legislation in China, but we think policy makes may as well enact reimbursement policy for rare disease patients to address the impoverishment of rare diseases. In this case, covering rare diseases in the health care system and paying the health expenditure by multiple sources may be an effective solution to ease the burden for patients with rare diseases. WHO suggests that in developing countries, the cost for prolonging a quality adjusted life year (QALY) is acceptable when it is less than 3 times of the average GDP per capita [24]. In 2014, China's GDP per capita has reached 46,629 yuan [12], so the acceptable cost for each QALY can be as high as almost 140,000 yuan, making it practical to cover the rare diseases with effective treatment and moderate expenses in the health care system. Besides, China should fully negotiate and make use of social resources, encourage the NGOs and companies to donate and set up a payment pattern so that health care funds, patients and third parties can share the expenses in order to reduce the ratio of out-of-pocket (OOP) expenditure. In this way, more patients may probably afford proper medical care, and the problem of poverty caused by disease could also be solved.

The three methods applied in evaluating the affordability of rare diseases and orphan drugs all have certain limitations. The annual per capital income method uses residents' annual income as indicator in calculation. However, the huge gap between the rich population and the poor makes average income an ineffective index to describe the affordability condition of the general public. With current data, we can specify the evaluation into five different groups by their income level, but this is still not satisfying in reflecting the conditions of some rich groups and the poor. As for catastrophic expenditure method, it uses the threshold $40 \%$ defined by WHO standards. As treatment is usually more expensive for rare diseases, the threshold can be lifted accordingly. For calculation in both catastrophic expenditure and impoverishment expenditure method, the distribution curves of urban and rural annual per capita disposable income. When fitting the income curve, we assume that for each income group, the income is in linear distribution, which may lead to an overestimated affordability for some low income groups and an underestimated affordability for some high income groups [25].

Furthermore, there is no registration system for rare disease or nationwide epidemiological survey on rare disease in China, so the prevalence rate used in this study is from Orphanet. Most rare diseases are genetic diseases and characterized by district and race, which might cause biases for the catastrophe rate and impoverishment rate in China (e.g. if the prevalence rate is higher in China, catastrophe rate and impoverishment rate would be underestimated). Thus there is an urgent need to establish registration system for rare disease, collecting data like prevalence rate data and providing evidence for policy making and implement. The three methods share a common assumption in calculation that the patients need to cover the health expenditure all by themselves, neglecting the circumstances where expenditures could be co-paid by other sources, thus underestimating the actual affordability of patients. Some districts in China have covered certain rare diseases in the health care system. In Qingdao, a city in Shandong province, patients of PAH and GD can have part of the expenses reimbursed. In Shanghai, 12 kinds of rare diseases such as phenylketonuria, maple syrup urine disease, and tyrosinemia have been covered by the city medical insurance [26]. Patients could receive a maximum of 200,000 yuan per year as reimbursement for health expenditure. 


\section{Conclusion}

Our results shows that the affordability of treatment for rare disease is rather poor. Residents of different income levels all have difficulties to afford the treatment for rare diseases. Rare disease could easily impoverish patients and their families. Therefore, social security mechanism for rare disease patients should be established and specific payment pattern for orphan drugs should be set up. To reduce OOP health expenditure of patients, the copayment pattern, led by government medical insurance and supported by medical aid, social charity and commercial insurance, is recommended.

\section{Additional file}

Additional file 1: Catastrophic expenditure and impoverishment of patients affected by 7 rare diseases in China. Table S1. Annual Disposable Income and Linear Equation for Each Group of Urban Population. Table S2. Annual Disposable Income and Linear Equation for Each Group of Rural Population. (DOC $42 \mathrm{~kb}$ )

\section{Abbreviations}

WHO, World Health Organization; HAl, health action international; LPGW, lowest paid unskilled Government Worker; DMD, Duchenne muscular dystrophy; AS, Alport syndrome; TSC, tuberous sclerosis complex; ALS, amyotrophic lateral sclerosis; IPF, idiopathic pulmonary fibrosis; $\mathrm{PAH}$, pulmonary arterial hypertension; GD, Gaucher disease

\section{Acknowledgements}

We are grateful for the cooperation and participation of all the ten experts from tertiary hospitals in Beijing.

\section{Funding}

Not applicable.

\section{Availability of data and materials}

The data set supporting the results of this article are included within the article and Additional file 1.

Additional file 1: Table S1. Annual Disposable Income and Linear Equation for Each Group of Urban Population \& Table S2. Annual Disposable Income and Linear Equation for Each Group of Rural Population. (Doc)

\section{Authors' contributions}

XXX carried out the literature search, did data analysis and drafted the manuscript. XDG and LWS supervised XXX and helped to write the manuscript. All authors read and approved the final manuscript.

\section{Competing interests}

The authors declare that they have no competing interests.

\section{Consent for publication}

Not applicable.

\section{Ethics approval and consent to participate}

Not applicable.

Received: 3 March 2016 Accepted: 19 May 2016

Published online: 06 June 2016

\section{References}

1. Liu X, Cui YZ, Li Y, Wang C, Zhao H, Han JX. Using inpatient data to estimate the prevalence of Wegener's granulomatosis in China. Intractable Rare Dis Res. 2016:5(1):31-5. doi:10.5582/irdr.2015.01015.

2. Gong SW, Jin S. Current progress in the management of rare diseases and orphan drugs in China. Intractable Rare Dis Res. 2012;1(2):45-52. doi:10.5582/irdr.2012.v1.2.45
3. Tao Y, Shao YF, Zhang C, Guo C, Lei L. The Past and Present of Orphan Drug Management System in US. Chin Pharm J. 2001;9:58-60. doi:10.3321/j. issn:1001-2494.2001.09.023.

4. Liu YC, Dong JP. Studies on Management Status of Rare Diseases and Orphan Drug in European Union. Chin Pharm J. 2012;47(5):395-8.

5. Gong SW. Study of Management Strategies of Improving Access to Orphan Drugs in China. Hubei: Huazhong University of Science and Technology, 2008. doi: 10.7666/d.d066054.

6. Song PP, Gao JJ, Inagaki Y, Kokudo N, Tang W. Intractable and rare diseases research in Asia. Biosci Trends. 2012;6(2):48-51. doi:10.5582/bst.2012.v6.2.48.

7. Cameron A, Ewen M, Ross-Degnan D, et al. Medicine prices, availability, and affordability in 36 developing and middle-income countries: a secondary analysis. Lancet. 2008;373:240-9. doi:10.1016/S0140-6736(08)61762-6.

8. Xu K, Evans DB, Kawabata K, et al. Household catastrophic health expenditure: a multicountry analysis. Lancet. 2003;362:111-7. doi:10.1016/ S0140-6736(03)13861-5.

9. Wagstaff A, Van Doorslaer E. Catastrophe and impoverishment in paying for health care: with applications to Vietnam 1993-98. Health Econ. 2003;12: 921-34. doi:10.1002/hec.776.

10. Rare Diseases Search. Paris: Orphanet 2015. (http://www.orpha.net/consor/ cgi-bin/Disease.php?lng=EN) Accessed 20 Nov 2015.

11. Designing Health Financing Systems to Reduce Catastrophic Health Expenditure. Geneva: World Health Organization, 2015. (http://apps.who.int/iris/bitstream/ 10665/70005/1/WHO_EIP_HSF_PB_05.02_eng.pdf) Accessed 12 Oct 2015.

12. 2015 Chinese Statistical Yearbook. Beijing: National Bureau of Statistics of China, 2015. (http://www.stats.gov.cn/tjsj/ndsj/2015/indexch.htm) Accessed 2 Dec 2015.

13. Guan XD. Research on National Essential Medicine Policy Evaluation in China. Beijing: Peking University; 2011.

14. 2014 Statistical Bulletin of Social Service Development. Beijing: Ministry of Civil Affairs of the People's Republic of China. (http://www.mca.gov.cn/ article/sj/tjgb/201506/201506008324399.shtml) Accessed 2 Dec 2015.

15. Simoens S. Pricing and reimbursement of orphan drugs: the need for more transparency. Orphanet J Rare Dis. 2011;6:42. doi:10.1186/1750-1172-6-42.

16. Arhin-Tenkorong D. Mobilizing resource for health: the case for user fees revisited. (http://www.cid.harvard.edu/cidwp/pdf/081.pdf) Accessed 16 Sept 2015.

17. Bidani B, Ravallion M. Decomposing social indicators using distributional data. J Econ. 1997;77:125-39. doi:10.1016/S0304-4076(95)01809-3.

18. Wagstaff A. Poverty and health sector inequalities. Bull World Health Organ. 2002;80:97-105.

19. Gansu government. Gansu Health and Family Planning Commission reported the epidemiological investigation results of five chronic epidemic diseases. (http://www.gansu.gov.cn/art/2014/8/19/art_36_193018.html) Accessed 5 Dec 2015.

20. Feng J, Xia ZG. Analysis of trends in cases of malaria reported form 2004 to July 2013 in People's Republic of China. J Pathog Biol. 2014;5:442-6.

21. Creese A, Kuznets J. Lessons from cost recovery in health: forum on health sector reform. WHO/SHS/NHP/95.5. Geneva: World Health Organization; 1997.

22. Gilson $\mathrm{L}$. The lessons of user fee experience in Afirca. Health Policy Plan. 1997;12:273-85. doi:10.1093/oxfordjournals.heapol.a018882.

23. Gong SW, Wang YX, Pan XY, et al. The availability and affordability of orphan drugs for rare diseases in China. Orphanet J Rare Dis. 2016;11:20. doi:10.1186/s13023-016-0392-4

24. Choosing Interventions that are Cost Effective (WHOCHOICE), Threshold values for intervention cost-effectiveness by Region. Geneva: World Health Organization, 2015. (http://www.who.int/entity/choice/costs/CER_ thresholds_regions.xls) Accessed 25 Sept 2015.

25. Niëns LM, Van de Poel E, Cameron A, et al. Practical measurement of affordability: an application to medicines. Bull World Health Organ. 2012; 90(3):219-27. doi:10.2471/BLT.10.084087.

26. Gao JJ, Song PP, Tang W. Rare disease patients in China anticipate the sunlight of legislation. Drug Discov Ther. 2013;7(3):126-8. doi:10.5582/ddt.2013.v7.3.126. 